\title{
Cultivation and Use of Acidithiobacillus ferrooxidans in Tellurium Biorecovery
}

Nicolas Daniel Hoffman

December 2020

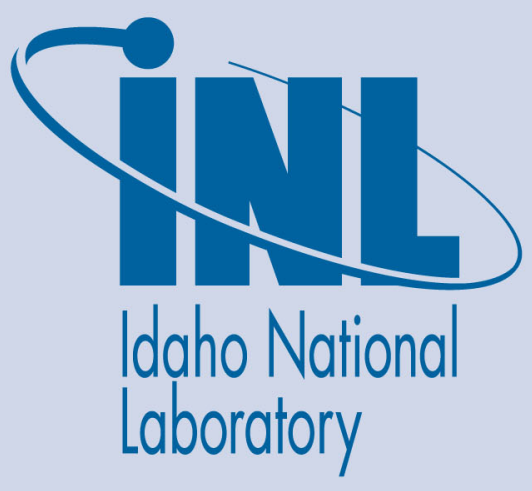

The INL is a U.S. Department of Energy National Laboratory operated by Battelle Energy Alliance 


\title{
Cultivation and Use of Acidithiobacillus ferrooxidans in Tellurium Biorecovery
}

\author{
Nicolas Daniel Hoffman
}

December 2020

Idaho National Laboratory Idaho Falls, Idaho 83415

http://www.inl.gov

Prepared for the U.S. Department of Energy

Office of Energy Efficiency and Renewable Energy Under DOE Idaho Operations Office

Contract DE-AC07-05ID14517 


\title{
Cultivation and Use of Acidithiobacillus ferrooxidans in Tellurium Biorecovery
}

\author{
Nicolas Hoffman \\ Office of Science, Science Undergraduate Laboratory Internship (SULI) Program \\ Brigham Young University-Idaho, Rexburg, ID \\ Idaho National Laboratory, Idaho Falls, ID
}

December 2020

Prepared under the direction of Yoshiko Fujita and David Reed in the Biological Science Department at Idaho National Laboratory. 


\section{TABLE OF CONTENTS}

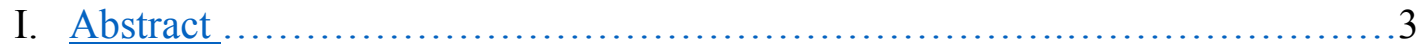

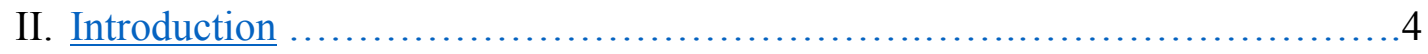

III.Methods ...................................................................... 5

a. DSMZ 882, DSMZ 35, and 9K Medium Preparation......................5

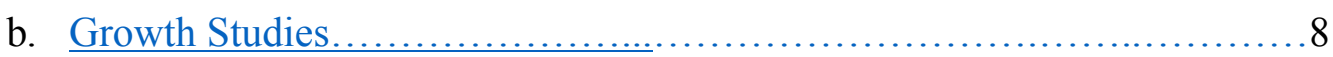

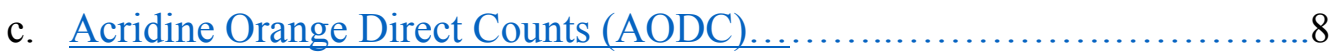

d. Measurement of Soluble Iron.......................................... 8

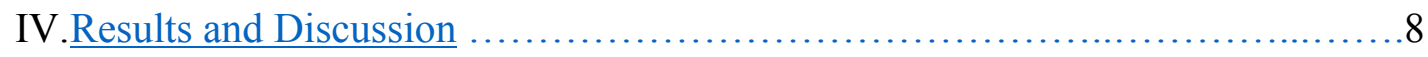

a. Cell Densities of A. ferrooxidans in DSMZ 882 and 9K Media.............10

b. Cell Density of A. ferrooxidans in 9K Medium .............................11

c. Standard Curve Generated from $\mathrm{Fe}^{2+}$ Standards........................11

d. Ferrozine Measurements Over Time Compared with Growth..............12

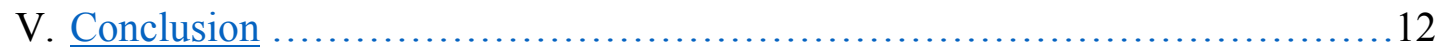

VI.Acknowledgments .................................................... 13

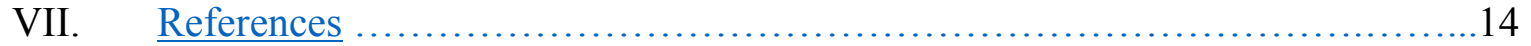




\section{ABSTRACT}

The use of Acidithiobacillus ferrooxidans, Thiobacillus thiooxidans, and other chemoautotrophic microbes in bioleaching have been implemented in a variety of processes. ${ }^{1}$ In industry, bioleaching has been studied for its potential to extract valuable metals from low grade ores that would otherwise be cost prohibitive to recover. $\stackrel{2}{ }$ Other applications of bioleaching include the ability of certain microbes to detoxify waste products and even heavy metal contaminated soils. ${ }^{3}$ Another potential application for such bio-oxidative microbial activity is the extraction of tellurium (Te) from mine tailings, a low-cost abundant resource. Tellurium is one of the least common elements on Earth; it is found in the planetary crust at about $1 \mu \mathrm{g} / \mathrm{kg}$, a rarity most comparable to that of platinum. ${ }^{4}$ A major use of Te in the U.S. is in cadmiumtelluride $(\mathrm{CdTe})$ solar panels ${ }^{5}$. Te is primarily imported into the U.S. from Canada, and it is usually recovered as a byproduct of copper refining. ${ }^{6}$ Since CdTe photovoltaic (PV) cells are the most efficient, cost-effective, and environmentally friendly PV chemistry, the renewables market has seen an increased demand for CdTe PV cells causing some concerns about sustainability and the limited global availability of Te. Acidithiobacillus ferroxidans is a microorganism that can oxidize iron and sulfur to produce ferric iron and sulfuric acid, and it is possible that it could also solubilize Te from sulfidic mine tailings. In this project, different media for growth of $A$. ferroxidans were evaluated, and a plan for testing the ability of $A$. ferroxidans to leach Te from mine tailings was developed. Initial characterization of $A$. ferroxidans cultures grown in the presence of copper tailings suggests that conditions suitable for Te bioleaching can be established. 


\section{INTRODUCTION}

This project aims to conduct initial studies of whether the well-known bacterium Acidithiobacillus ferrooxidans can promote Te solubilization from sulfidic mine tailings.

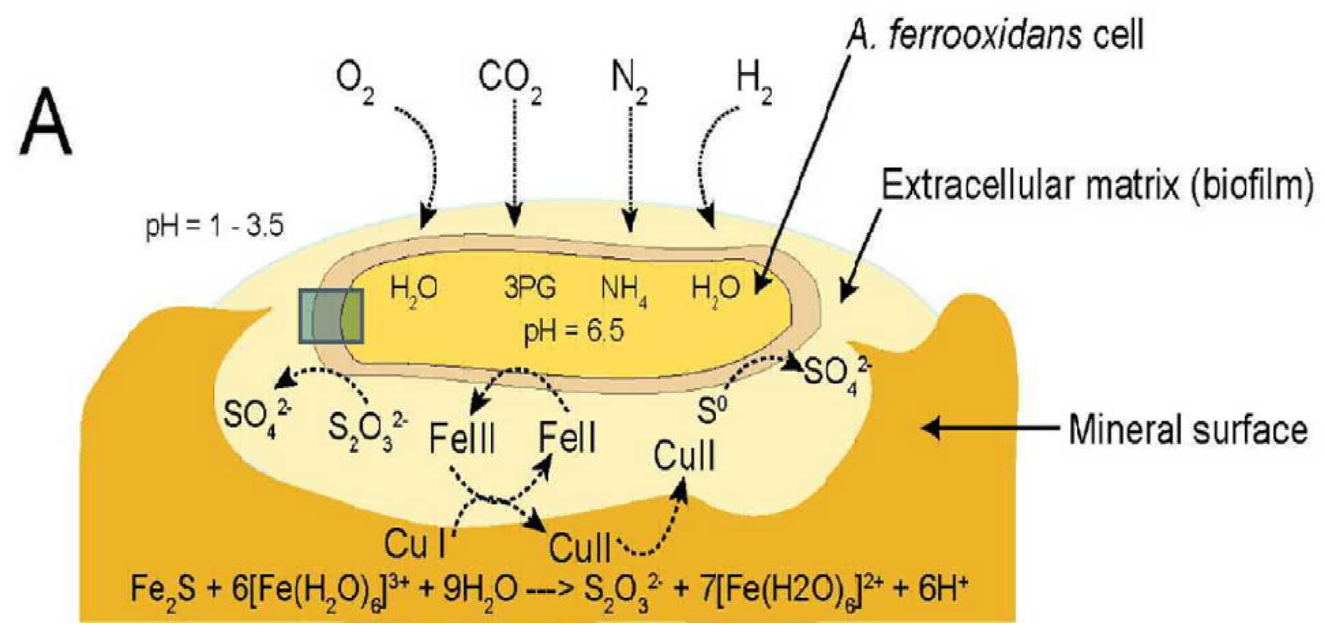

Figure 1: A. ferrooxidans proposed bioleaching mechanism of copper sulfide ores.

A. ferrooxidans oxidizes $\mathrm{Fe}^{2+}$ to $\mathrm{Fe}^{3+}$ (Fig 1). The $\mathrm{Fe}^{3+}$ can then abiotically oxidize copper within the copper sulfides, allowing for solubilization of the valuable ore. This is the process known as "bioleaching," and the main objective in future experiments is to determine if tellurium is also recovered in this same manner. This paper outlines suitable conditions for such a tellurium bioleaching experiment. The first step was to determine the best microbiological media for growing A. ferrooxidans and for conducting the leaching studies. Three different media were prepared: A. ferrooxidans was grown in three standard media types: DSMZ 882, DSMZ 35, and 9K. To monitor growth and activity, cell numbers were determined by acridine orange direct counts (AODC) and soluble iron was measured using the Ferrozine assay (Stookey, 1970). The Ferrozine 
assay measures soluble $\mathrm{Fe}^{2+} ; \mathrm{Fe}^{3+}$ and total soluble iron can also be determined by reduction of $\mathrm{Fe}^{3+}$ to $\mathrm{Fe}^{2+}$. Our hypothesis is that if $\mathrm{A}$. ferrooxidans is able to oxidize high concentrations of $\mathrm{Fe}^{2+}$ to $\mathrm{Fe}^{3+}$, then the oxidative conditions necessary for indirect $\mathrm{Te}$ bioleaching will be microbially created.

\section{METHODS}

a. DSMZ 882, DSMZ 35, and 9K medium preparation:

To prepare a solution of DSMZ 882 medium, all the reagents in Table 1 were combined while stirring to a final volume of $2 \mathrm{~L}$ with $\mathrm{npH}_{2} \mathrm{O}$ and sterile technique. The DSMZ 882 was prepared in three separate parts, as per the recipe, and not mixed until solutions $\mathrm{A}, \mathrm{B}$, and $\mathrm{C}$ were completed and sterilized/filtered. These solutions were aseptically added into a 2L final container. In preparing the DSMZ 35 medium, two variations of DSMZ 35 were tested. Each DSMZ 35 medium contained a different sulfur source. The sulfur sources were: tyndallized elemental sulfur, and sodium thiosulfate. Mixing instructions were the same as indicated in Table 2, apart from the indicated sulfur source. For the 9K medium, Solutions A and B (Table 3) were prepared separately, allowing Solution B to be autoclaved while Solution A was filter-sterilized using a 0.20 $\mu \mathrm{m}$ PES bottle-top filter unit (Millipore). See Table 3 for the steps used in the 9K media preparation. During preparation of all three media types, certain ingredients were not available in the lab, and there was a need to slightly adjust which reagent was used. For example, the DSMZ 882 media in Table 1 shows that the recipe called for $147.0 \mathrm{mg}$ of 
calcium chloride dihydrate. However, only the anhydrous form was available in the lab, so $110 \mathrm{mg}$ of anhydrous calcium chloride was used in order to provide an equimolar concentration of the necessary reagent.

Table 1: DSMZ 882 Media Preparation

\section{DSMZ Medium 882 as follows:}

Solution A:

(NH4)2SO4

$132.0 \mathrm{mg}$

$\mathrm{MgCl} 2 * 6 \mathrm{H} 2 \mathrm{O}$

$53.0 \mathrm{mg}$

$\mathrm{KH} 2 \mathrm{PO} 4$

$27.0 \mathrm{mg}$

$\mathrm{CaCl} 2 * 2 \mathrm{H} 2 \mathrm{O} *$ Replace the dihydrous with $110 \mathrm{mg}$ of anhydrous* $147.0 \mathrm{mg}$

Distilled Water

$950.0 \mathrm{ml}$

Adjust to $\mathrm{pH} 1.8$ with $10 \mathrm{~N}(\mathbf{5 M}) \mathrm{H} 2 \mathrm{SO} 4$

Solution B:

$\mathrm{FeSO} 4 * 7 \mathrm{H} 2 \mathrm{O}$

$20.0 \mathrm{~g}$

$0.25 \mathrm{~N} \mathrm{H} 2 \mathrm{SO} 4$ (0.125 M)

$50.0 \mathrm{ml}$

The $\mathrm{pH}$ of this solution should be 1.2

Solution C:

Trace elements solution (see below) $\quad 1.00 \mathrm{ml}$

Mixing Instructions:

Sterilize Solutions A and C by autoclaving at $112 \mathrm{C}$ for $30 \mathrm{~min}$. Prior to use, mix Solutions A, B, and $\mathrm{C}$. The final $\mathrm{pH}$ of the medium should be 1.8. Incubate statically without shaking.

Trace Elements Solution:

$\mathrm{MnCl} 2 * 4 \mathrm{H} 2 \mathrm{O} \quad 76.0 \mathrm{mg}$

$\mathrm{ZnCl} 2$ * Replace the $\mathrm{ZnCl} 2$ with $143.5 \mathrm{mg}$ of $\mathrm{ZnSO} 4 * 7 \mathrm{H} 20$ due to availability* $68.0 \mathrm{mg}$

$\mathrm{COCl} 2 * 6 \mathrm{H} 2 \mathrm{O}$

$64.0 \mathrm{mg}$

$\mathrm{H} 3 \mathrm{BO} 3$

$31.0 \mathrm{mg}$

$\mathrm{Na} 2 \mathrm{MoO} 4 *_{\text {found }}$ as dihydrate, so $11.9 \mathrm{mg}$ of the dihydrate* $10.0 \mathrm{mg}$

$\mathrm{CuCl} 2 * 2 \mathrm{H} 2 \mathrm{O}$

$67.0 \mathrm{mg}$

Distilled Water $1000.0 \mathrm{ml}$

Table 2: DSMZ 35 Media Preparation

DSMZ Medium 35 as follows:

$\mathrm{NH} 4 \mathrm{Cl}$

$0.10 \mathrm{~g}$

$\mathrm{KH} 2 \mathrm{PO} 4 \quad *$ See Solution A ingredients* $3.00 \mathrm{~g}$

$\mathrm{MgCl} 2 * 6 \mathrm{H} 2 \mathrm{O} *$ See Solution A ingredients* $0.10 \mathrm{~g}$ 
$\mathrm{CaCl} 2 * 2 \mathrm{H} 2 \mathrm{O} *$ See Solution A ingredients. Replace w/ 0.105g anhydrous* $0.14 \mathrm{~g}$ Sulfur, powdered * Replace w/ 77.4g sodium thiosulfate pentahydrate* $\quad 10.00 \mathrm{~g}$ Distilled Water $1000.00 \mathrm{ml}$

Mixing Instructions:

Dissolve all ingredients, except the sulfur source, and adjust to $\mathrm{pH} 4.2$ with $.125 \mathrm{M} \mathrm{H} 2 \mathrm{SO} 4$, then autoclave. For sterilization, place the sulfur in screw-capped tubes or bottles, wet with a few drops of water, and then heat for 3 hours to 90-100C in a water bath on each of the three successive days. Before use, aseptically layer the sulfur onto the surface of autoclaved liquid basal medium. Incubate statically without shaking.

Table 3: 9K Media Preparation

\begin{tabular}{|c|c|c|c|c|}
\hline Reagents: & $\begin{array}{l}\text { Solution } \\
1\end{array}$ & Ammonium Sulfate & $3.0 \mathrm{~g}$ & Lot\# 030M0139 \\
\hline & & K2HPO4 (anhydrous) & $0.5 \mathrm{~g}$ & Lot\# 974351 \\
\hline & & $\begin{array}{l}\text { Magnesium } \\
\text { Heptahydrate }\end{array}$ & $0.5 \mathrm{~g}$ & Lot\# 025626 \\
\hline & & Potassium Chloride & $0.1 \mathrm{~g}$ & Lot\# 072772 \\
\hline & & $\mathrm{Ca}(\mathrm{NO} 3) 2$ & $0.01 \mathrm{~g}$ & $\begin{array}{l}\text { Batch\# } \\
18620 \text { CB }\end{array}$ \\
\hline & & NanoPure Water & $700 \mathrm{~mL}$ & \\
\hline & $\begin{array}{l}\text { Solution } \\
2\end{array}$ & Iron (II) Sulfate Heptahydrate & $\begin{array}{l}44.22 \\
\mathrm{~g}\end{array}$ & Lot\# MKCJ9113 \\
\hline & & NanoPure Water & $300 \mathrm{~mL}$ & \\
\hline
\end{tabular}

Mixing instructions:

1. Beginning with Solution 1 , add the ingredients together and then adjust the $\mathrm{pH}$ to 5.5 with drops of $5 \mathrm{M} \mathrm{H} 2 \mathrm{SO} 4$.

2. Then, autoclave Solution 1 at $120 \mathrm{C}$ on setting 3 (LIQ40)

3. Solution 2, add the iron (II) sulfate to the $\mathrm{npH} 2 \mathrm{O}$

4. Adjust $\mathrm{pH}$ to 1.4 with $5 \mathrm{M} \mathrm{H} 2 \mathrm{SO} 4$.

5. Then, filter sterilize Solution 2.

6. After Solution 1 cools from autoclaving, combine both solutions into a $1 \mathrm{~L} \mathrm{screw-cap}$ container.

7. Adjust final $\mathrm{pH}$ (between 1.5-2.0.) using the $\mathrm{pH}$ electrode.

8. Because the $\mathrm{pH}$ electrode is not clean, a sterile filtration of the entire medium into a final container is the last step.

9. Final medium should be a clear blue color (no precipitate). 
b. Growth studies:

Initially, A. ferrooxidans was inoculated as a $5 \%(\mathrm{v} / \mathrm{v})$ inoculum with a final volume of $20 \mathrm{~mL}$ in all 3 media types. A. ferrooxidans used in the following analyses was obtained from Michael Guzman at LLNL. This strain was viable and grew in $9 \mathrm{~K}$ and 882 . No growth of $A$. ferrooxidans was observed in either of the DSMZ 35 media. Initial inoculation of the cultures used an inoculum ratio of $1: 20(1 \mathrm{~mL}$ of inoculum into $19 \mathrm{~mL}$ of media) was used, then a ratio of 1:50 (1mL of inoculum and 49mL of media) was used for growth studies. Static incubation was attempted initially with the nonviable strains, but not with the viable strain acquired from LNLL. Growth conditions were controlled with the temperature at $30 \mathrm{C}$, shaking at $150 \mathrm{rpm}$, and growth media $\mathrm{pH} 1.8-2.0$.

c. Acridine Orange Direct Counts (AODC):

Samples for AODC cell enumerations were prepared by mixing $900 \mathrm{uL}$ of culture with $100 \mathrm{uL}$ of acridine orange solution containing $54 \mathrm{uL} 37 \%$ formaldehyde. Acridine orange stains the DNA of the bacteria for observation under a fluorescence microscope. The stained cells were filtered onto a nylon membrane placed atop a cellulose filter under vacuum suction. Counting was performed on a $0.01 \mathrm{~mm}$ grid $(100 \mu \mathrm{m} \times 100 \mu \mathrm{m})$. The diameter of the stained area was $16.5 \mathrm{~mm}$ with a stained area of $213.82 \mathrm{~mm}^{2}$, at 21.382 grids/filter. The fluorescence microscope was a A15 Nikon 1000X; the excitation and emission wavelengths were: blue light/green fluorescence = Excitation (Ex) 480nm +/$30 \mathrm{~nm}$ and the Emission (Em) $535 \mathrm{~nm}+/-40 \mathrm{~nm}$ with the dichronic selectivity filter (Tm) 
at 505; green light/orange fluorescence $=$ Ex 540/25 and Em 605/55, and Tm at 565, respectively. The number of cells/field was calculated as an average across various fields until at least 300 cells had been counted.

d. Measurement of soluble iron:

Soluble iron was measured via the Ferrozine assay (Stookey, 1970). The reagents used were $\mathrm{HCl} 1 \mathrm{M}, 0.1 \%(\mathrm{w} / \mathrm{v})$ Ferrozine reagent in 50\% (w/v) ammonium acetate (stored in the dark at 4C), and hydroxylamine hydrochloride (HAHC) $10 \%(\mathrm{w} / \mathrm{v})$ in $1 \mathrm{M}$ $\mathrm{HCl}$. The dissolved $\mathrm{Fe}^{2+}$ reacts with the Ferrozine reagent and turns purple; the higher the ferrous concentration the darker the purple color, which is measured using a spectrophotometer at $562 \mathrm{~nm}$. A calibration curve was generated using ammonium ferrous sulfate hexahydrate in $1 \mathrm{M} \mathrm{HCl}$. $\mathrm{HCl}$ and Ferrozine reagent was used as the blank. A $100 \mathrm{uL}$ sample was diluted into $900 \mathrm{uL}$ of $1 \mathrm{M} \mathrm{HCl}$ and vortexed. Then, $100 \mathrm{uL}$ of this solution was added to a cuvette, along with $900 \mathrm{uL}$ of $1 \mathrm{M} \mathrm{HCl}$ and $1000 \mathrm{uL}$ of Ferrozine reagent. After $10 \mathrm{mins}$, the absorbance was measured at $562 \mathrm{~nm}$ and recorded.

\section{RESULTS AND DISCUSSION}

Growth from laboratory stocks was not observed by wet mount. It was determined that the laboratory strain could not be revived by any of the above media types. $A$. ferrooxidans used in the following analyses was obtained from Michael Guzman at LLNL. Growth curves comparing A. ferrooxidans growth in DSMZ 882 and 9K media show higher cell densities are achieved by growth in the $9 \mathrm{~K}$ medium as compared to growth in the DSMZ 882 medium over 
the same period of time (196 hours). (Fig. 2) Growth was slow and linear in the DSMZ 882 medium, and growth appeared to be much greater in the $9 \mathrm{~K}$ medium. In a separate growth experiment, A. ferrooxidans was inoculated in 9K medium to determine what cell densities could be reached. Growth was observed to be logarithmic and inflection points were seen after 48 hours and significantly after 96 hours of incubation time. (Fig. 3) This indicated that after 96 hours of growth, the bacteria had entered their stationary phase of growth. The standard curve generated for the Ferrozine assay was used to calculate the concentrations of $\mathrm{Fe}^{2+}$ and had an $\mathrm{R}$ value of 0.9999 , indicating a high accuracy of measurement. (Fig. 4) The Ferrozine assay applied to the $9 \mathrm{~K}$ culture medium showed that after 96 hours, the amount of detectable ferrous iron was dramatically decreased as compared to the uninoculated $9 \mathrm{~K}$ medium as a positive control. (Fig. 5)

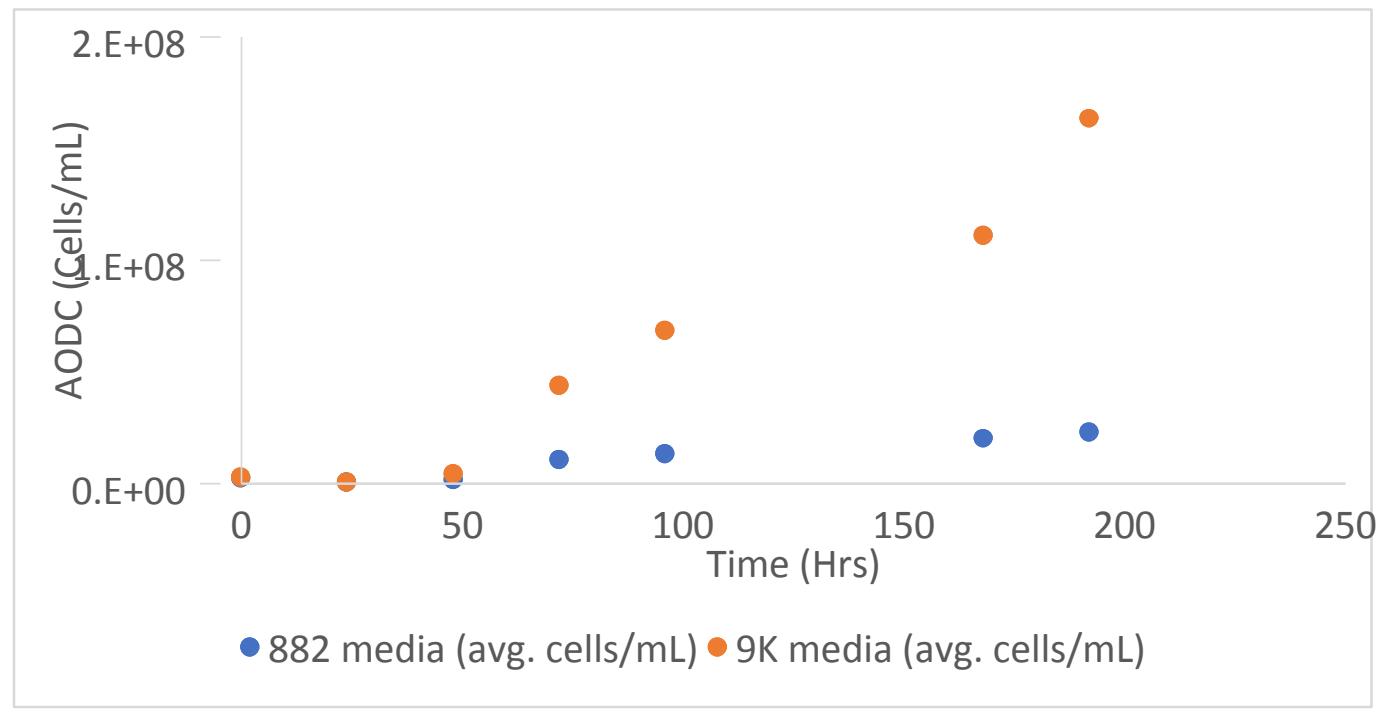

Figure 2: Cell densities of A. ferrooxidans in DSMZ 882 and 9 K media 
Idaho National Laboratory

Cultivation and Use of Acidithiobacillus ferrooxidans in Tellurium Biorecovery | 11

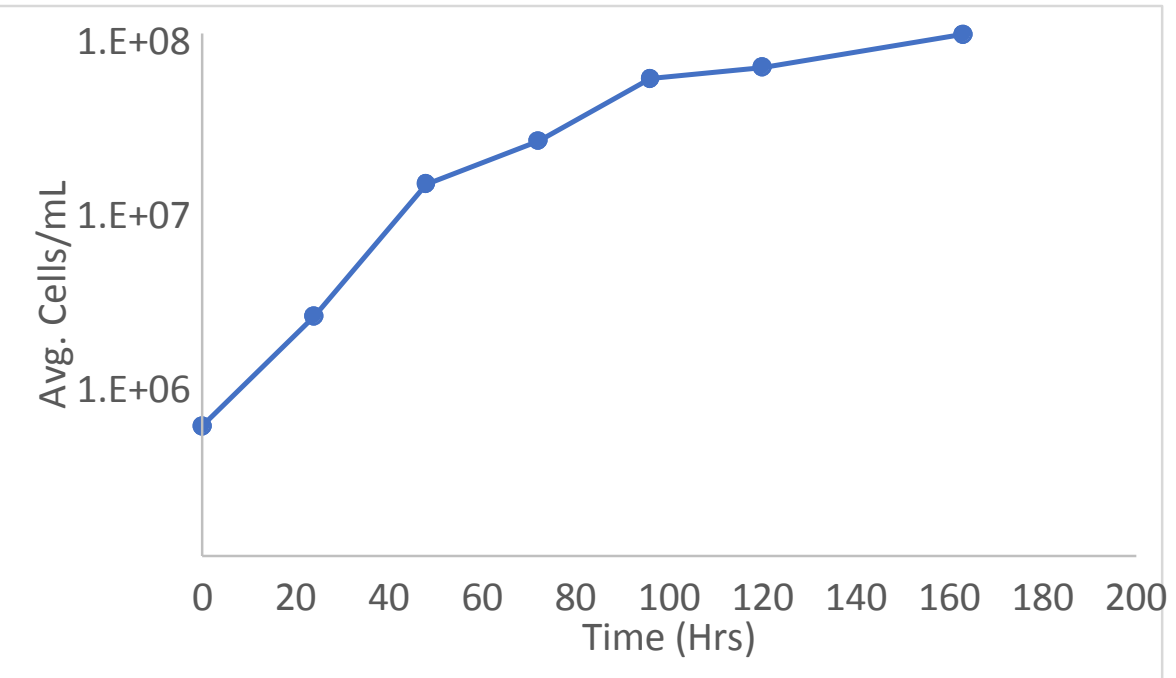

Figure 3: Cell density of $A$. ferrooxidans in $9 K$ medium

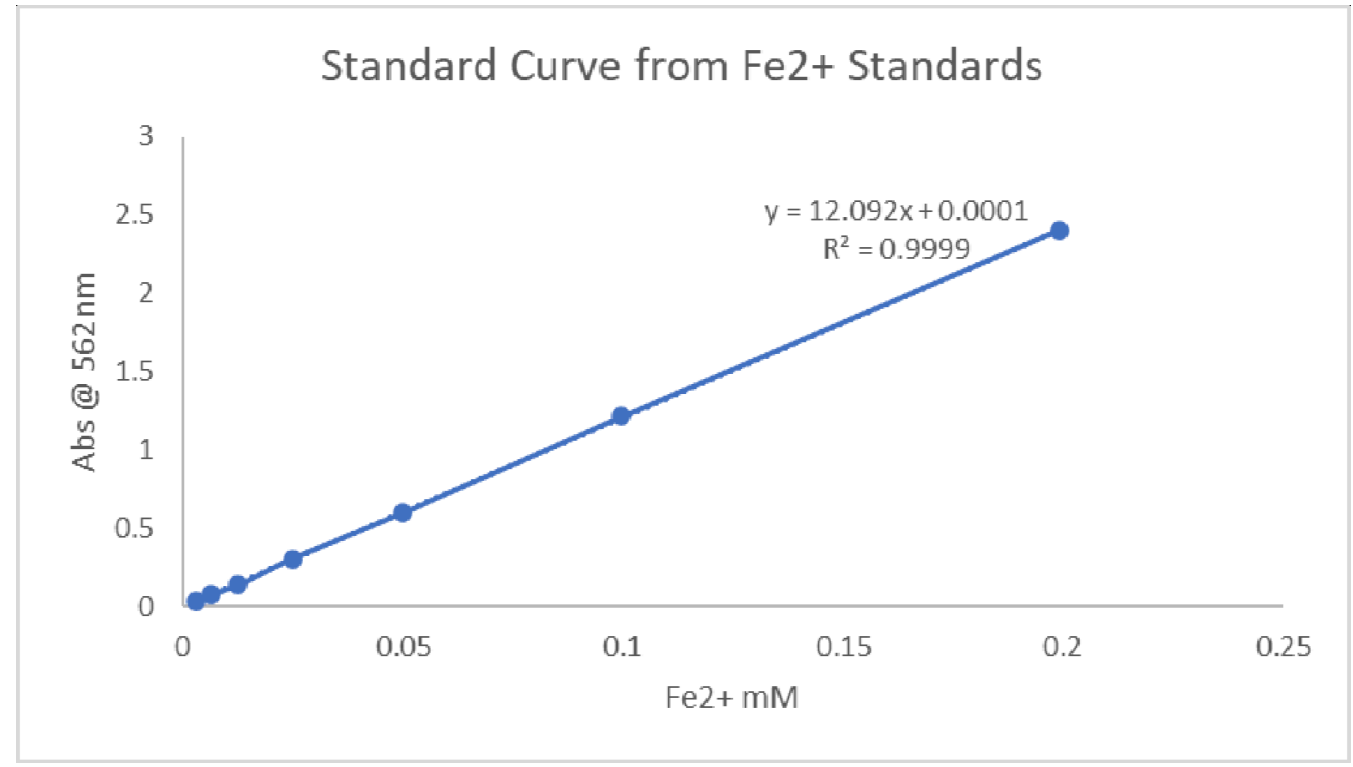

Figure 4: Standard curve generated from $\mathrm{Fe}^{2+}$ standards 


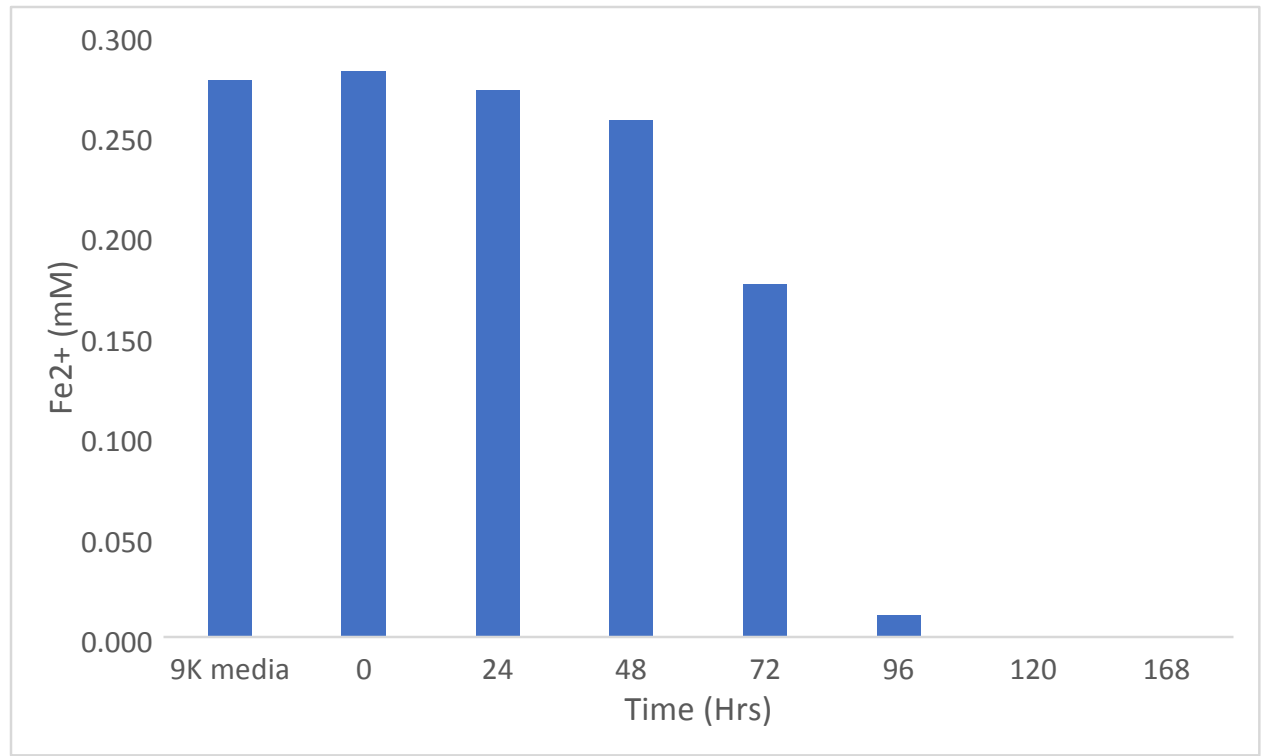

Figure 5: Ferrozine measurements of $9 K$ cultured with A. ferrooxidans incubated for 168 hours

\section{CONCLUSIONS}

As evidenced by the growth analysis of Acidithiobacillus ferrooxidans in $9 \mathrm{~K}$ media, optimal cell density was achieved under the following incubation conditions: temperature at 30C, shaking at 150rpm, $\mathrm{pH} 1.8-2.0$, and after a period of at least 96 hours incubation. The incubation conditions were not varied in this experiment, however future optimization experiments may involve adjusting these parameters. The time point of 96 hours was identified to be a sufficient starting point for preliminary bioleaching studies based on the results in Figures 3 and 5. Although there is an inflection point in Figure 3 after the first 48 hours, it is not until after 96 hours that the doubling time of the bacteria significantly increases. At these conditions, cell densities of $1.64 \times 10^{8}$ were achieved in the lab with the $9 \mathrm{~K}$ medium. These greater cell densities are beneficial for bioleaching studies, corresponding to higher levels of potential biooxidative activity. Likewise, after 96 hours of culture growth in the $9 \mathrm{~K}$ medium, the amount of detectable ferrous iron was dramatically decreased, indicating that $A$. ferrooxidans was in fact 
oxidizing virtually all the ferrous iron into ferric iron (Fig 5). This oxidation activity is exactly what we would expect to see during a bioleaching experiment as we seek to leach Te from sulfidic minerals found in mine tailings. Actual Te biorecovery will be tested in future experiments, but the results reported here will serve to inform the selection of the bioleaching conditions to be applied in future experiments at INL.

\section{ACKNOWLEDGMENTS}

I'd like to acknowledge mentors Dr. Yoshiko Fujita and Dr. David W. Reed from the Idaho National Laboratory for their guidance and direction during the course of my internship. Thanks are also due to the Critical Materials Institute (CMI), the Department of Energy (DOE), and the Idaho National Laboratory (INL) for providing me the opportunity to participate in research through the Science Undergraduate Laboratory Internship (SULI) program. I would also like to acknowledge Caitlin McNamara for her encouragement and guidance during my time here at INL. Funding was provided at INL through DOE Idaho Operations Office Contract DE-AC07-05ID14517.

\section{REFERENCES}

1. Olson GJ, Brierley JA, Brierley CL. Bioleaching review part B: progress in bioleaching: 
applications of microbial processes by the minerals industries. Appl Microbiol Biotechnol. 2003 Dec;63(3):249-57. doi: 10.1007/s00253-003-1404-6. Epub 2003 Oct 18. PMID: 14566430.

2. Annamalai, M., Gurumurthy, K. Enhanced bioleaching of copper from circuit boards of computer waste by Acidithiobacillus ferrooxidans. Environ Chem Lett 17, 1873-1879 (2019). https://doi.org/10.1007/s10311-019-00911-y

3. Consuelo Gomez, Klaus Bosecker (1999) Leaching Heavy Metals from Contaminated Soil by Using Thiobacillus ferrooxidans or Thiobacillus thiooxidans, Geomicrobiology Journal, 16:3, 233-244, DOI: 10.1080/014904599270613

4. Ayres, Robert U.; Ayres, Leslie (2002). A handbook of industrial ecology. Edward Elgar Publishing. p. 396. ISBN 1-84064-506-7.

5. SCI CSS patent: Foote et al. Process for making photovoltaic devices and resultant product, United States Patent 5248349; and their vapor transport patent, featuring the movement of vaporized cadmium and tellurium atoms through a closed, silicon carbide distributor: Apparatus and method for depositing a semiconductor material, United States Patent 6037241. Both are now owned by First Solar.

6. Minerals Commodity Summaries. 2020. USGS. http://pubs.usgs.gov/periodicals/mcs2020/mcs2020.pdf. Pages 166-167

7. Reed, D. W.; Fujita, Y.; Daubaras, D. L.; Jiao, Y.; Thompson, V. S., 2016. Bioleaching of 


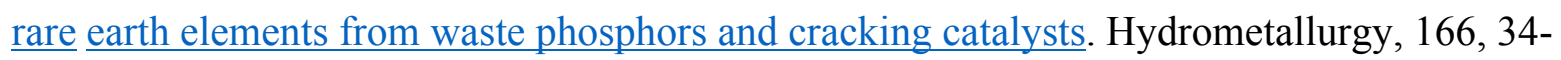
40.

8. Thompson, Vicki \& Gupta, Mayank \& Jin, Hongyue \& Vahidi, Ehsan \& Yim, Matthew \& A Jindra, Michael \& Nguyen, Van \& Fujita, Yoshiko \& Sutherland, John \& Jiao, Yongqin \& Reed, David. (2017). Techno-economic and Life Cycle Analysis for Bioleaching Rare Earth Elements from Waste Materials. ACS Sustainable Chemistry \& Engineering. 6.10.1021/acssuschemeng. 7b02771.

9. Stookey, Lawrence L. Ferrozine---a new spectrophotometric reagent for iron. Analytical Chemistry 197042 (7), 779-781. DOI: 10.1021/ac60289a016 